\section{ECCOMAS}

\section{Proceedia}

COMPDYN 2021

$8^{\text {th }}$ ECCOMAS Thematic Conference on Computational Methods in Structural Dynamics and Earthquake Engineering M. Papadrakakis, M. Fragiadakis (eds.) Streamed from Athens, Greece, 28 - 30 June 2021

\title{
ASSESSMENT OF POST-EARTHQUAKE DAMAGES ON ITALIAN SCHOOL BUILDING PORTFOLIOS OVER THE LAST 50 YEARS
}

\author{
Sergio Ruggieri ${ }^{1}$, Chiara Tosto ${ }^{1}$, Daniele Perrone ${ }^{2,3}$, Giuseppina Uva ${ }^{1}$, Maria Antonietta \\ Aiello $^{2}$ \\ ${ }^{1}$ Polytechnic University of Bari \\ Via Amendola, 70126 Bari, Italy \\ \{sergio.ruggieri,chiara.tosto,giuseppina.uva\}@poliba.it \\ ${ }^{2}$ University of Salento \\ Via per Monteroni, 73100 Lecce, Italy \\ \{daniele.perrone,antonietta.aiello\}@unisalento.it \\ ${ }^{3}$ University School for Advanced Studies IUSS Pavia \\ Piazza della Vittoria, 27100 Pavia, Italy \\ daniele.perrone@iusspavia.it
}

\begin{abstract}
The Italian peninsula has been subjected to several destructive earthquakes over the last 50 years which denoted the high vulnerability of the existing building stock. In this context, the analysis of post-earthquake damages is of paramount importance for manifold reasons, such as the management of the emergency phase for establishing the usability of buildings and the identification of the main sources of vulnerability for future risk mitigation plans. Since about 50 years, the post-earthquake usability of buildings is assessed through simplified forms filled by experts and practitioners during extensive in-situ inspections. The data collected during the post-earthquake inspections have been recently catalogued in the Observed Damage Database (DA.D.O), which is a freely available platform for the scientific community. Starting from the data available in the DA.D.O platform, the damage reported by Italian school buildings have been analyzed in order to elaborate a proper school buildings database. The results of this statistical investigation are used for identifying the main sources of vulnerability characterizing the Italian school buildings and assuming a key role for the empirical calibration of reliable procedures of large-scale seismic risk assessment, mapping and reduction.
\end{abstract}

Keywords: Risk Assessment, School Buildings, Post-Earthquake Damages, DA.D.O platform. 


\section{INTRODUCTION}

The post-earthquake inspections made after major earthquakes in the Mediterranean area highlighted the high vulnerability of building portfolios, especially with regard to existing structures built before the introduction of seismic provisions in national and international building codes. In Italy, the damages observed after the major seismic events occurred over the last 50 years raised the awareness of public institutions, researchers and practitioners about the vulnerability of existing buildings and the need for a large-scale seismic risk assessment to promote seismic risk mitigation programs [1-6]. Within this framework, the scientific community has developed several empirical and analytical procedures to define vulnerability curves for different building typologies, e.g. reinforced concrete (RC) buildings [7-11], masonry buildings [12-13], precast buildings [14], based on post-earthquake damage observations. Specific studies dealing with the seismic vulnerability assessment of relevant building typologies, such as schools [15-17], hospitals [18] and ecclesiastic heritage [19-22] are also available. Among the most common approaches adopted to assess and mitigate seismic risk, it is worthwhile mentioning also mechanical-based approaches [23-25], rapid visual screening (RVS) methodologies [26-27] and hybrid methods.

Empirical methods consist in the statistical processing of data about damages observed after past earthquakes. The data analysis allows to estimate the probability of occurrence of a certain damage state for increasing seismic intensities. The final output is represented by fragility curves, which can be considered vulnerability curves if a certain quantification of the expected losses is taken into account in the adopted intensity measure (IM). Over the years, several empirical-based vulnerability functions have been developed by referring to different building typologies. Qualitative and quantitative measures have been adopted to define the IM used in the vulnerability curves. In particular, the most widely adopted quantitative measure is the peak ground acceleration (PGA), while for the qualitative measures, some macro-seismic scales are defined, such as the Modified Mercalli Intensity (MMI), Medvedev-SponheuerKarnik (MSK) and Mercalli-Cancani-Sieberg (MCS). Qualitative and quantitative measures are often freely available online for different seismic events [28-29].

The damage probability matrix (DPM) proposed by Braga et al. [30] was one of the first empirical methods to be developed. It consists in the definition of the discrete probability that a certain damage - measured according to a macro-seismic scale - occurs in the total sample of investigated buildings. Braga et al. adopted the MSK scale to apply the DPM method to RC buildings damaged by the Irpinia earthquake (1980). Rossetto and Elnashai [31] proposed empirical fragility curves for RC buildings using a database of about 350.000 units. Di Pasquale et al. [32] developed a loss model based on the damage observed during past earthquakes in Italy. Lagomarsino and Giovinazzi [33] proposed, for several building typologies in the Mediterranean area, a methodology for relating macro-seismic and mechanical models for vulnerability assessment, basing on post-earthquake observations. Recent works [6-22] have refined the empirical methodologies and the related vulnerability and fragility curves by using large samples of buildings damaged by recent earthquakes. A useful tool for analyzing the damage occurred after Italian earthquakes has been recently developed by the Italian Department of Civil Protection: the Observed Damage Database (DA.D.O) web-gis platform, which collects the results of post-earthquake inspections made after the major Italian earthquakes.

Using the data available in DA.D.O. platform, the present study focuses on the assessment of damages occurred in Italian school buildings after the main Italian seismic events over the last 50 years. All data have been firstly extracted from DA.D.O. platform and then processed by taking into account some typological parameters, such as construction typology, year of construction, number of storeys, area and structural regularity. Once all data have been orga- 
nized in a specific database, they have been processed for a twofold scope: (a) providing a statistical quantification of the damaged school buildings and their main typological features; (b) providing vulnerability curves, according to the defined building classification.

\section{DA.D.O. PLATFORM: A DATA COLLECTION OF EARTHQUAKE RELATED DAMAGE OVER THE LAST 50 YEARS IN ITALY}

The Da.D.O. web-gis platform has been conceived with the specific purpose to collect, catalogue and compare data related to damage and structural characteristics of buildings inspected after earthquakes occurred in Italy over the last 50 years. Data from ten seismic events characterized by a high seismic intensity are provided [34]: Friuli 1976; Irpinia 1980; Abruzzi 1984; Umbria-Marche 1997; Pollino 1998; Molise 2002; Emilia 2003; L'Aquila 2009; Emilia 2012, Garfagnana 2013. A summary of the general information present in the database is provided in Del Gaudio et al. [8], which reports that the total number of inspected buildings amounts to 320.000 , subdivided among $78 \%$ of masonry buildings, $8 \%$ of RC buildings and $14 \%$ for other construction typologies. Since the survey forms have been modified over the years, the information available for each seismic event can vary. Presently, postearthquake inspections are carried out by using the AeDES form [36], which was firstly introduced following the Umbria-Marche 1997 event. Previously, different survey forms were adopted (former versions of the AeDES form). For each seismic event collected in the Da.D.O. platform, Table 1 reports the key information accessible for each building. In particular, the information available in each survey form can be summarized in five macro-sections:

1. Building registry: general information and location of the buildings (e.g. year of construction, latitude and longitude, municipality, census code);

2. Geometry: main typological and geometrical features (e.g. number of storeys, qualitative estimate of area, inter-storey height);

3. Use destination: information about the use of the building from stakeholders (e.g. building use, number of occupants, strategic destination);

4. Position in urban context: information about the position of the building (e.g. reference with the position of near buildings, soil and topography);

5. Construction typology: main structural features (e.g. construction material, presence of retrofit devices, regularity).

The level of completeness and the quality of the data depends on the seismic events, more detailed information being available for more recent earthquakes. Table 1 reports a general indication about the level of detail of the recorded information distinguishing between: complete (C), incomplete (I) and absent (A) information. Regarding the building registry, all survey forms contain some details, however, for the first three considered events (Friuli 1976, Irpinia 1980 and Abruzzi 1984), the latitude and longitude are referred to the municipality in which the buildings are located and not to the specific location of the analyzed building. Concerning the geometry, the survey forms used after the first three events only report the plan dimension, while from the Irpinia 1980 earthquake the number of storeys and inter-storey height are also available. Only the data about the Abruzzi 1984 earthquake do not report the inter-storey height. The forms used in the first three events did not provide details about the use of the buildings, while for the Umbria-Marche 1997 and the Pollino 1998 earthquakes this information is reported, allowing to classify the buildings also based on their strategic importance. With regard to the position in the urban context, the form used in the Friuli 1976 earthquake reports if the building is isolated, outer-edge or in the corner of other building complexes. Only in the case of the Irpinia 1980 and the Abruzzi 1984 earthquakes, this data is 
not reported. Lastly, with reference to the construction typology, complete information is provided for all seismic events but for the first three events only the construction material is reported.

\begin{tabular}{lccccc}
\hline Seismic event & $\begin{array}{c}\text { Building regi- } \\
\text { stry }\end{array}$ & Geometry & $\begin{array}{c}\text { Use destina- } \\
\text { tion }\end{array}$ & $\begin{array}{c}\text { Position in } \\
\text { urban context }\end{array}$ & $\begin{array}{c}\text { Construction } \\
\text { typology }\end{array}$ \\
\hline Friuli 1976 & I & I & A & I & I \\
Irpinia 1980 & I & C & A & A & I \\
Abruzzi 1984 & I & I & A & A & I \\
Umbria-Marche 1997 & C & C & I & C & C \\
Pollino 1998 & C & C & I & C & C \\
Molise 2002 & C & C & C & C & C \\
Emilia 2003 & C & C & C & C & C \\
L'Aquila 2009 & C & C & C & C & C \\
Emilia 2012 & C & C & C & C & C \\
Garfagnana 2013 & C & C & C & C & C \\
\hline
\end{tabular}

Table 1: Summary of the key information reported in the survey forms adopted after the Italian seismic events occurred over the last 50 years (information about damage data are herein excluded)

As for the details related to the identification of the building's features, also the damage classification is related to the survey form adopted for the post-earthquake inspections. The forms used for the first three considered seismic events (Friuli 1976, Irpinia 1980 and Abruzzi 1984) do not allow to identify the damage extension [8]. The form adopted following the Friuli 1976 earthquake only allowed to classify buildings based on their global damage state, while more detailed information was introduced in the forms adopted during the following earthquakes. In particular, starting from the Pollino 1998 earthquake, it was possible to collect details about the damage state of five building components (vertical structures, horizontal structures, stairs, roofs and infill panels or non-structural elements). Table 2 reports the damage levels adopted in each survey form by grouping the different damage states in four main sub-categories. More in detail, the survey form adopted after the Friuli 1976 earthquake provides a synthetic judgement about observed damages (from destroyed to undamaged) subdivided in five damage levels (L0-L4). The survey form adopted after the Irpinia 1980 earthquake presents eight damage levels (L0-L7), while in the case of Abruzzi 1984 earthquake, the damage state was classified distinguishing between five damage levels (L1-L5) defined according to the EMS98 scale. From the Umbria-Marche 1997 earthquake, the AeDES survey form was introduced and the damage levels were classified according to damage states (D) defined according to the EMS98 scale.

It is worth mentioning that in the DA.D.O platform the details provided by the Institute of Geophysics and Vulcanology (INGV) for the characterization of the seismic events are also reported. This data includes: shake maps [37], date, magnitude, distance, geographic position (epicentre and hypocentre) and macro-seismic intensities in terms of Mercalli-CancaniSieberg scale (IMCS) [38].

\begin{tabular}{lccccc}
\hline Seismic event & Damage levels & $\begin{array}{c}\text { Heavy dama- } \\
\text { ges }\end{array}$ & $\begin{array}{c}\text { Medium da- } \\
\text { mages }\end{array}$ & $\begin{array}{c}\text { Light } \\
\text { damages }\end{array}$ & $\begin{array}{c}\text { Null } \\
\text { damage }\end{array}$ \\
\hline Friuli 1976 & 5 & L3-L4 & L2 & L1 & L0 \\
Irpinia 1980 & 8 & L5-L6-L7 & L3-L4 & L1-L2 & L0 \\
Abruzzi 1984 & 5 & L4-L5 & L2-L3 & L1 & $/$ \\
Umbria-Marche 1997 & 3 & D4-D5 & D2-D3 & D0-D1 & $/$
\end{tabular}


Sergio Ruggieri, Chiara Tosto, Daniele Perrone, Giuseppina Uva, Maria Antonietta Aiello

\begin{tabular}{llllll} 
Pollino 1998 & 4 & D4-D5 & D2-D3 & D1 & D0 \\
Molise 2002 & 4 & D4-D5 & D2-D3 & D1 & D0 \\
Emilia 2003 & 4 & D4-D5 & D2-D3 & D1 & D0 \\
L'Aquila 2009 & 4 & D4-D5 & D2-D3 & D1 & D0 \\
Emilia 2012 & 4 & D4-D5 & D2-D3 & D1 & D0 \\
Garfagnana 2013 & 4 & D4-D5 & D2-D3 & D1 & D0 \\
\hline
\end{tabular}

Table 2: Summary of the damage classification in the survey forms used after the main Italian seismic events, considering 4 macro-sections of damage: heavy, medium, light and null.

\section{SCHOOL BUILDINGS DAMAGED BY ITALIAN EARTHQUAKES: STATISTICAL ANALYSIS ON THE SPECIFIC-CLASS PARAMETERS}

Using the data available in the DA.D.O platform, all the school buildings damaged following the selected seismic events have been classified and statistically analysed. As reported in Table 1, the usage of the buildings was not available for seismic events occurred before 2002 . In order to identify the school buildings for all considered seismic events, the information provided by DA.D.O platform has been compared with the Open Data about Italian schools provided by Italian Ministry of University and Research (MIUR) [39]. For each damaged building, DA.D.O provides the latitude and the longitude, while the MIUR database provides the address and the municipality of all Italian school buildings. Using reverse geocoding algorithm [40], latitude and longitude of all Italian school buildings have been found and matched with latitude and longitude of the damaged buildings, by imposing a tolerance -in absolute value- to the fourth decimal place. The summary of the identified school buildings, subdivided for construction typology, is provided in Table 3.

\begin{tabular}{|c|c|c|c|c|}
\hline Seismic event & $\begin{array}{c}\text { Number of school build- } \\
\text { ings extracted by } \\
\text { DA.D.O. }\end{array}$ & $\mathrm{RC}[\%]$ & Masonry [\%] & $\begin{array}{l}\text { Other typolo- } \\
\text { gies }[\%]\end{array}$ \\
\hline Friuli 1976 & I & 1 & I & I \\
\hline Irpinia 1980 & l & l & l & / \\
\hline Abruzzi 1984 & 3 & 0.0 & 100.0 & 0 \\
\hline Umbria-Marche 1997 & 153 & 15.0 & 79.5 & 5.5 \\
\hline Pollino 1998 & 25 & 12.0 & 64.0 & 24.0 \\
\hline Molise 2002 & 248 & 48.8 & 35.1 & 16.1 \\
\hline Emilia 2003 & 17 & 0.0 & 88.2 & 11.8 \\
\hline L'Aquila 2009 & 616 & 54.7 & 27.8 & 17.5 \\
\hline Emilia 2012 & 577 & 34.9 & 44.7 & 20.4 \\
\hline Garfagnana 2013 & / & / & / & / \\
\hline
\end{tabular}

Table 3: Number of school buildings damaged by Italian seismic events over the last 50 years, accounting for the construction typology.

For Friuli 1976 earthquake, for the fixed tolerance, the matching procedure has not provided any useful results. The Irpinia 1980 earthquake, although several data are available, has been discarded because for this event the coordinates available are referred to the municipality and not to the specific location of the building. For Abruzzi 1984, Umbria-Marche 1997 and Pollino 1998 earthquakes, several units have been identified, as reported in Table 3. Although the adopted identification procedure can be affected by uncertainty, some random checks have been performed, observing a good level of accuracy. The distribution of the selected school buildings along the entire territory can be displayed using the extracted data. Figures 1 and 2 
report the identified school buildings for Pollino 1998 and Emilia 2013 earthquakes and, additionally, the IMCS for each municipality.

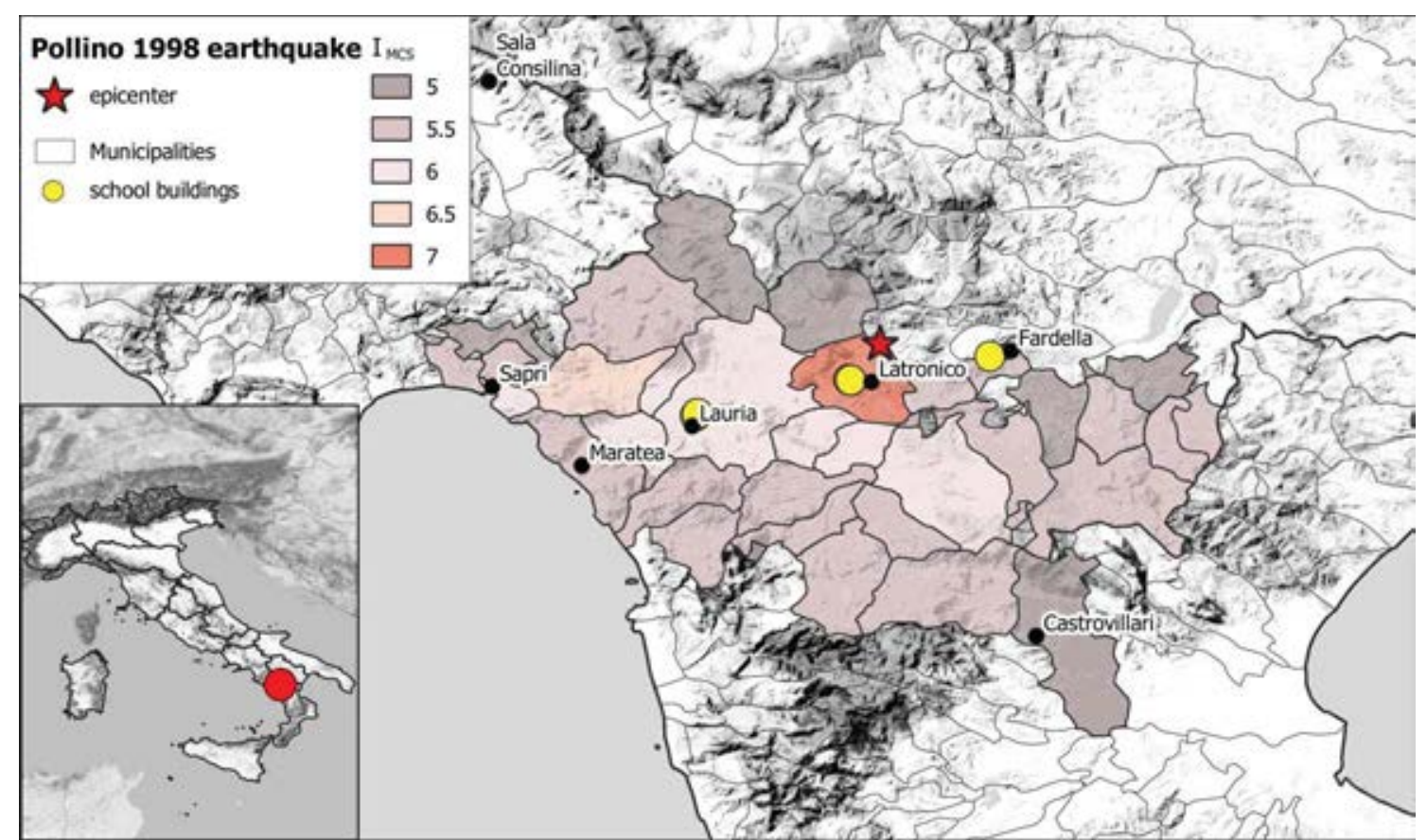

Figure 1: Distribution of school buildings damaged by Umbria-Marche 1997 earthquakes, with indication of $\mathrm{I}_{\mathrm{MCS}}$ for each municipality.

Based on the defined school building database, several observations can be made on damaged masonry and RC school buildings, with the aim to evaluate the entire school building portfolio damaged by recent Italian earthquakes. Firstly, the year of construction for masonry and RC school buildings has been analyzed (Figure 3) NC indicates the school for which this information was not available. As expected, about $75 \%$ of masonry units were built before 1961 and about $90 \%$ before 1980. A different situation is observed for RC school buildings, where about $60 \%$ of the units were built before 1980. In 1980, the first seismic building code was released in Italy. This aspect suggests that the greater part of masonry and RC school buildings was not designed according to seismic details, which highlight a high seismic vulnerability of the building portfolio. 


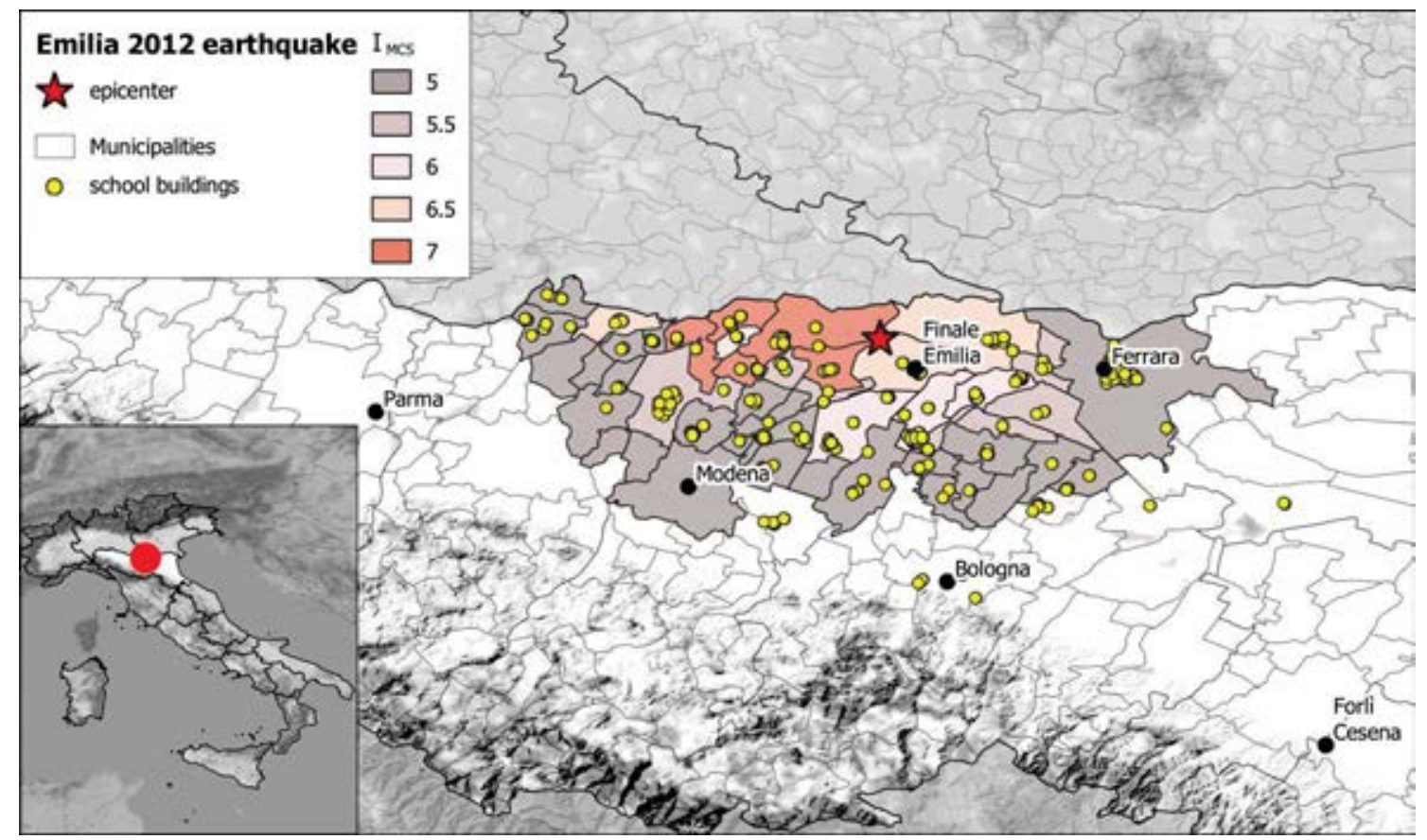

Figure 2: Distribution of school buildings damaged by Emilia 2013 earthquakes, with indication of $\mathrm{I}_{\mathrm{MCS}}$ for each municipality.
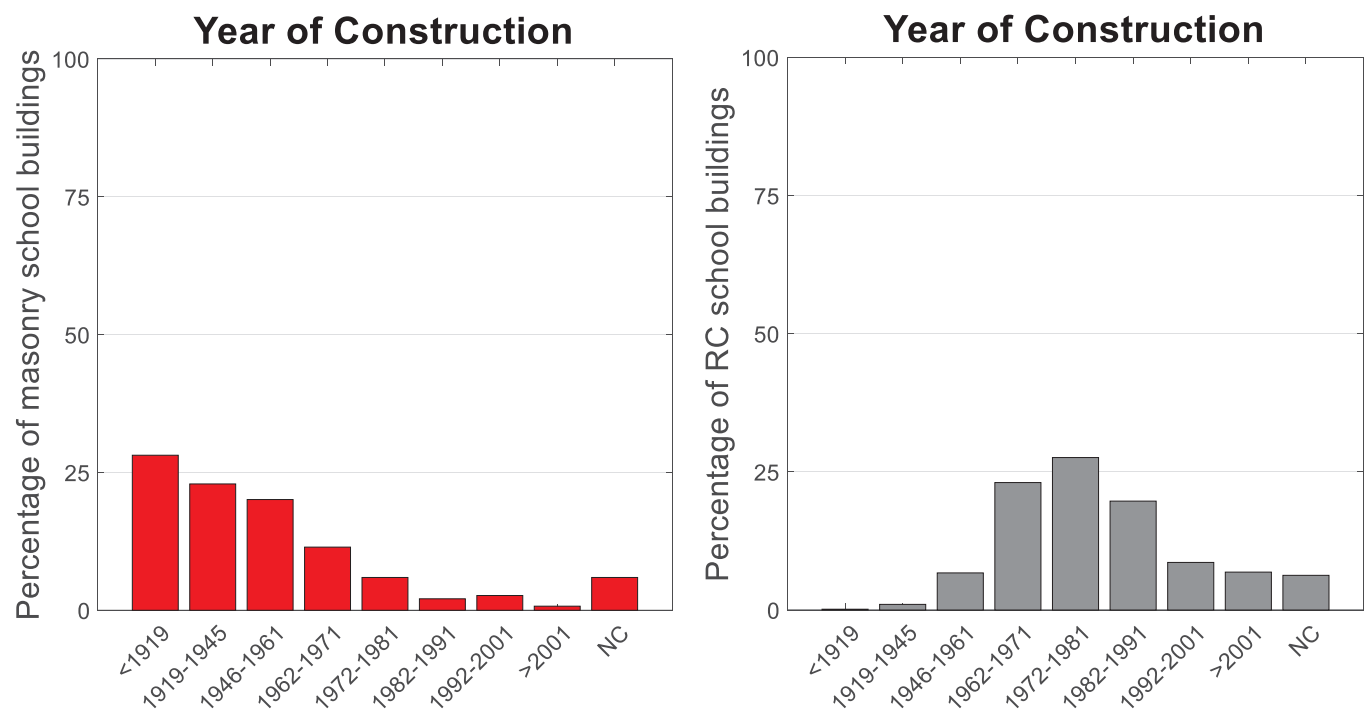

Figure 3: Percentage of masonry and RC school buildings, subdivided for year of construction parameter.

Figure 4 reports the number of storeys by distinguishing between masonry and $\mathrm{RC}$ buildings. Approximately $75 \%$ of the masonry and RC school buildings have three or fewer storeys. This observation implies that most of the damaged Italian school buildings can be classified as low-rise buildings (this evidence is also reported in several scientific works, e.g. $[25,27])$. No particular evidence can be extracted from the inter-storey height parameter: about $85 \%$ of the RC school buildings presents values that range from $2.50 \mathrm{~m}$ and $3.50 \mathrm{~m}$, while the remaining $15 \%$ presents higher values. The inter-storey height is more discretized for masonry buildings; higher inter-storey heights are observed in the schools built before $1920(>5.00 \mathrm{~m})$, while inter-storey heights ranging from $3.50 \mathrm{~m}$ to $5.00 \mathrm{~m}$ have been observed for more recent buildings. 

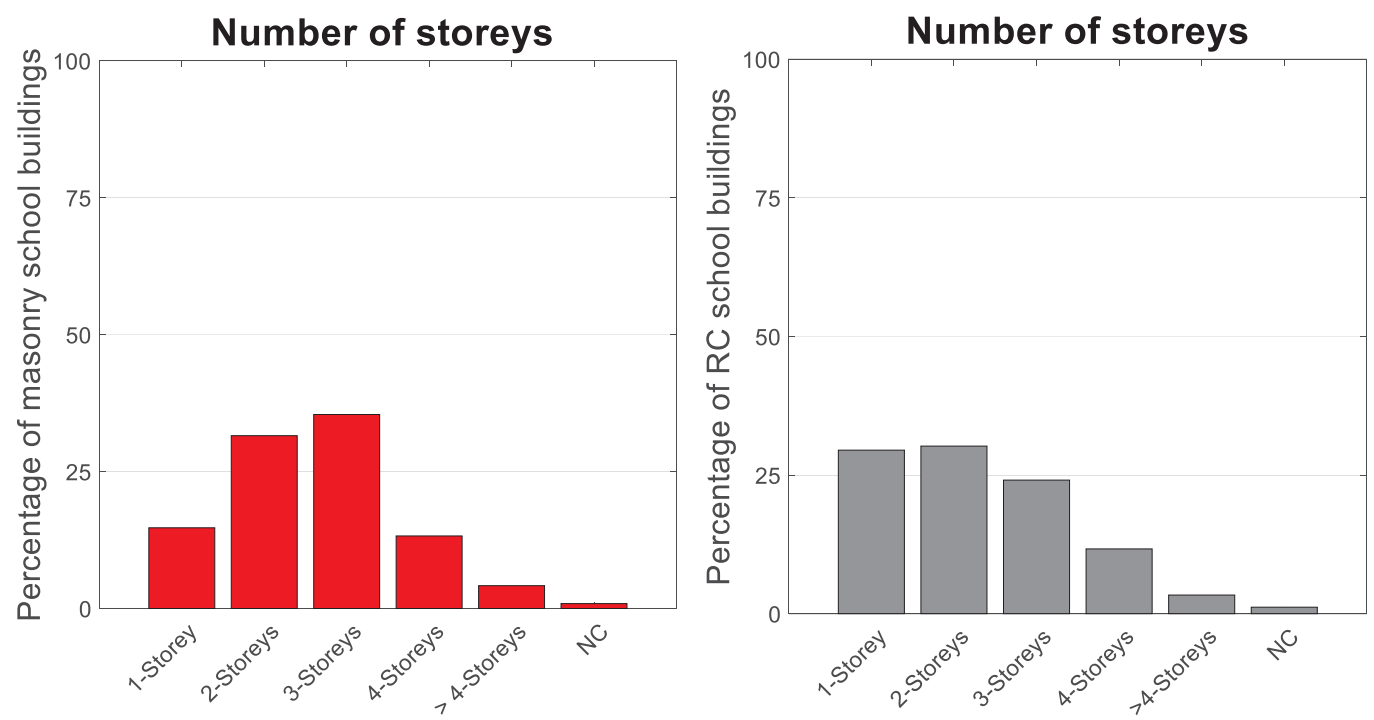

Figure 4: Percentage of masonry and RC school buildings, subdivided for number of storeys parameter.

Less homogenous is the distribution of the area parameter. As shown in Figure 5, about $40 \%$ of masonry school buildings and $25 \%$ of $\mathrm{RC}$ school buildings have an area ranging from 50 $\mathrm{m}^{2}$ to $300 \mathrm{~m}^{2}$, while about $50 \%$ of masonry and RC school buildings presents an area comprised from $300 \mathrm{~m}^{2}$ to $1200 \mathrm{~m}^{2}$. The high percentage of buildings characterized by large plan dimensions might suggests that this parameter can influence the seismic behavior.

As for the area parameter, also the structural regularity is an important parameter for defining the seismic vulnerability. This information is not available for all the units. In particular, the data available for school buildings damaged by Abruzzi 1984 and Umbria-Marche 1997 earthquakes do not report information on regularity and then they have been classified as NC. Looking at the percentage of regular and irregular school buildings, Figure 5 reports a summary for all the units. It is evident that about $50 \%$ of masonry and RC buildings presents structural irregularities. This aspect needs to be taken into account, considering that the structural irregularity assumes a key role in the seismic response of buildings.
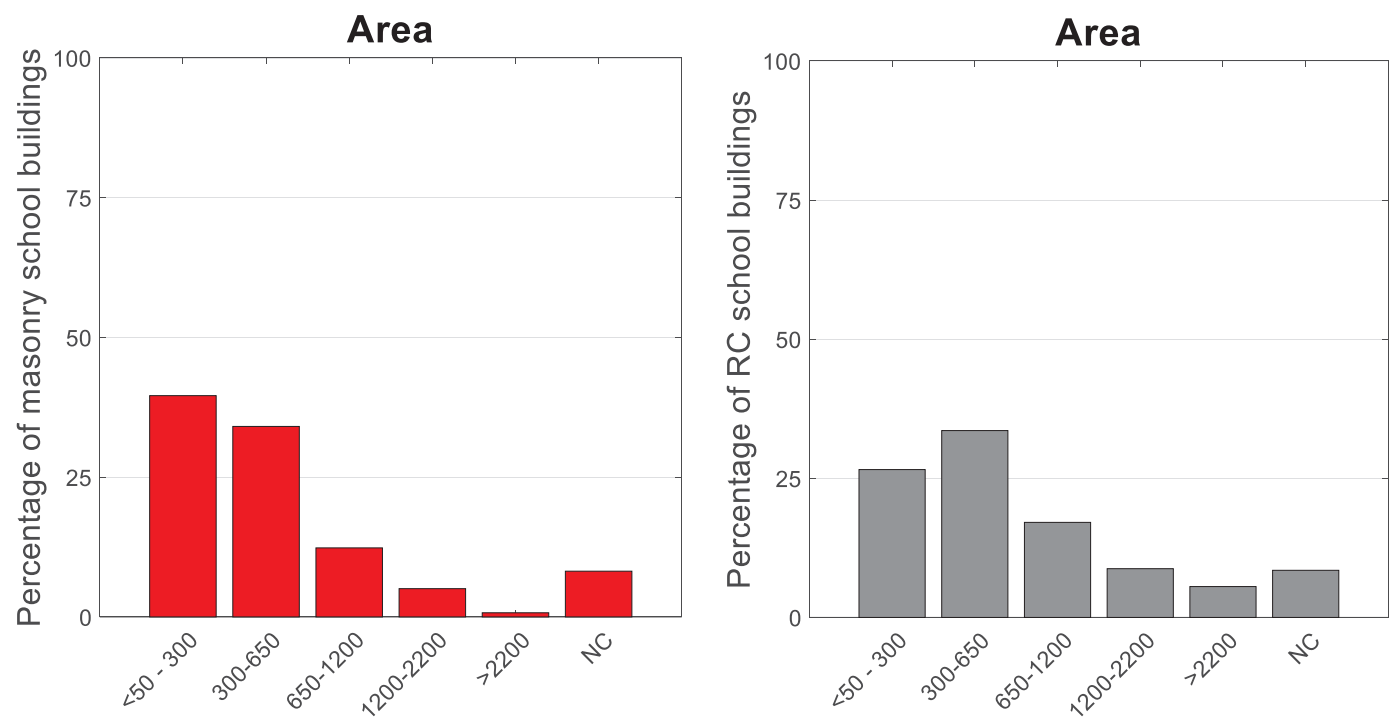

Figure 5: Percentage of masonry and RC school buildings, subdivided for area parameter. 

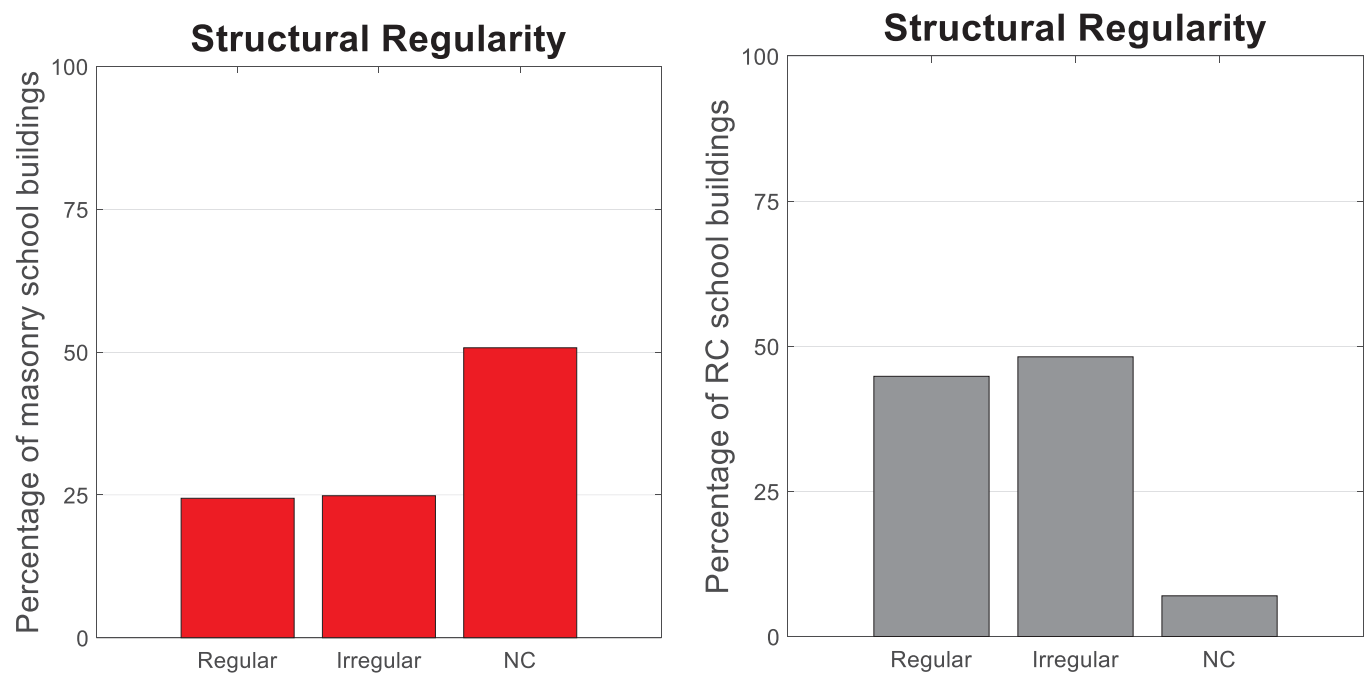

Figure 6: Percentage of masonry and RC school buildings, subdivided for structural regularity parameter.

\section{EMPIRICAL ESTIMATION OF THE SEISMIC BEHAVIOUR OF ITALIAN SCHOOL BUILDINGS: DAMAGE DISTRIBUTION AND VULNERABILITY CURVES}

The data collected in the DA.D.O. platform reports the results of the inspections made by practitioners and researchers rushed to the scene in the days after the earthquakes. As for rapid visual screening procedures, the definition of the damage state is based on the surveyors' experience, although some guidelines describing the different damage states are available. As previously discussed, it is worth mentioning that the survey forms adopted over the years can differ both in terms of investigated structural elements and damage classification. The survey form adopted in the Abruzzi 1984 earthquake contains judgments only about vertical and horizontal structures, while the one employed in the Umbria-Marche 1997 earthquake also considers damage to stairs. A complete information is provided for the Irpinia 1980 earthquake and for earthquakes after the Pollino 1998 and the Molise 2002 earthquake (AeDES form), in which damage data about vertical and horizontal structures, stairs, roofs and non-structural elements (such as infill panels for RC buildings) are present.

Basing on the developed school buildings database, it is possible to provide a critical discussion on the damages reported by school buildings after the selected earthquakes, by means of DPMs. Since the damages in AeDES form are classified according to the EMS98 scale, it is necessary to convert the damage levels reported for those earthquakes in which the AeDES form was not adopted (see Table 2) into the EMS98 measure scale. The methodology proposed by Del Gaudio et al. [8] has been adopted for the conversion into the EMS98 measure scale. Then, DPMs can be elaborated, as shown in Figures 7 and 8, accounting for horizontal structures, stairs, roofs and non-structural elements and by separating the RC and masonry school building samples. 

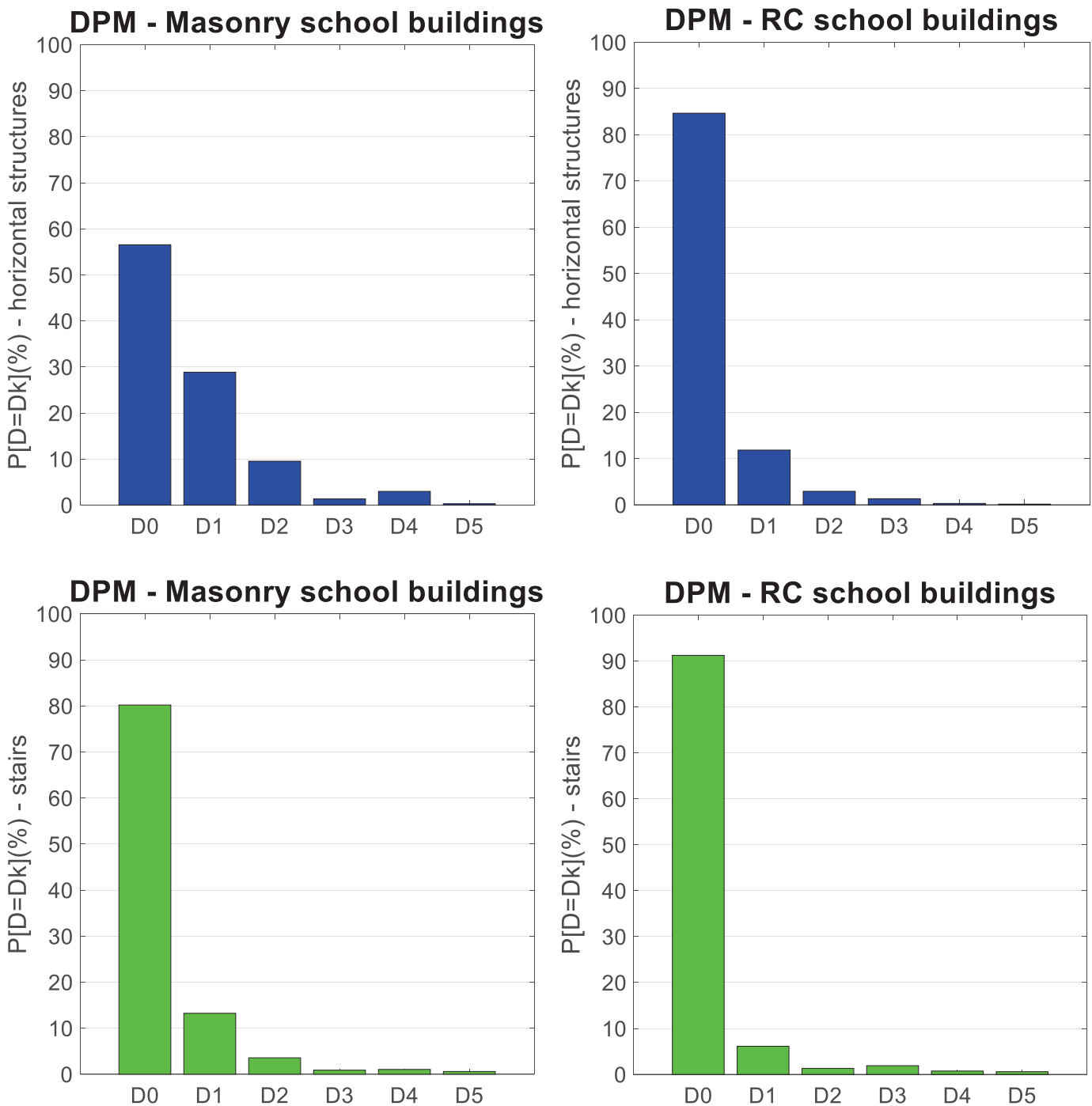

Figure 7: DPM for masonry and RC school buildings, accounting for damages on horizontal structures and stairs.

The results of the statistical analysis show that about $85-90 \%$ of the RC buildings have a damage level D0 and 10\% have a damage level D1, with regard to horizontal structures, stairs and roofs. Despite the sample was not sorted for year of construction, few damages were detected. Different evidence is shown for non-structural elements (e.g. masonry infill panels and partitions), which show about $40 \%$ of units having damage level D1 and about $20 \%$ having damage levels ranging from D2 to D5. For non-structural elements, similar percentages are reported for masonry school buildings, for which non-structural elements present damage levels greater than D0 for about 55\% of the units. Again for masonry buildings, DPMs show several damages on horizontal structures (about $45 \%$ of buildings have a damage level greater than D0), whereas few units present damages to stairs and roofs. 

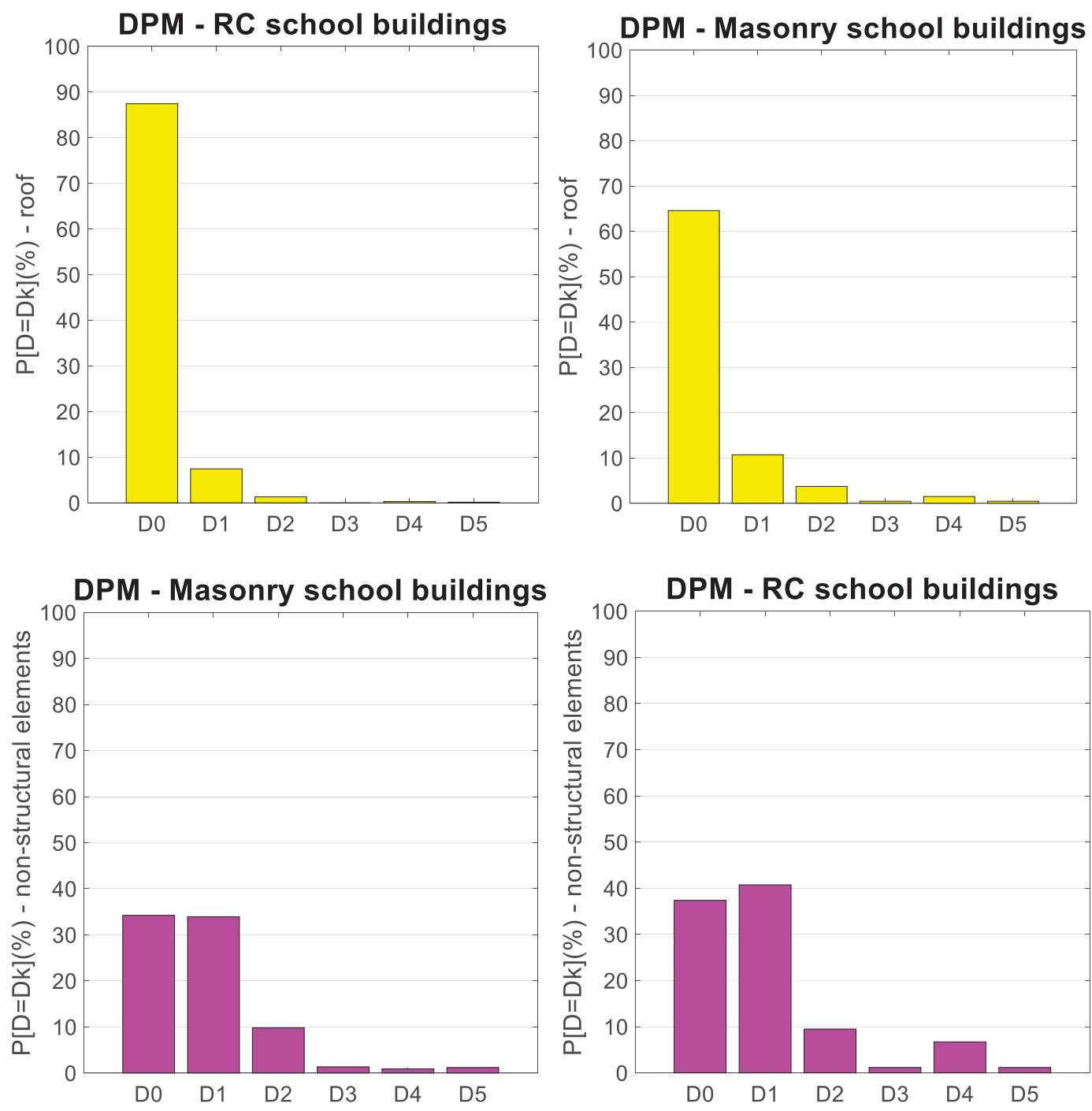

Figure 8: DPM for masonry and RC school buildings, accounting for damages on roofs and non-structural elements.

With regard to vertical structural elements, data can be processed by means of vulnerability curves. In particular, the entire set of school buildings has been subdivided into three samples: (a) Masonry school buildings, (b) RC school buildings designed before 1980 (pre 1980), (c) RC school buildings designed after 1980 (post 1980), by assuming 1980 as the threshold year that separate the buildings with and without seismic details. To this scope, for each unit of the three samples $\left(\mathrm{N}_{\text {units }}\right)$, damage data are reported in Figure 9, in which the abscissa reports the $I_{M C S}$ identified for each municipality and the ordinate reports the mean damage $\left(\mu_{D}\right)$, evaluated as the weighted average of the buildings having a certain damage "DS" equal to an assigned value of damage "ds". This formulation, as proposed in [8], is reported in the following:

$$
\mu_{D, j}=\frac{1}{5} \frac{\sum_{d s=0}^{5} N_{\text {units }}(D S=d s) \cdot d s}{\sum N_{\text {units }}}
$$




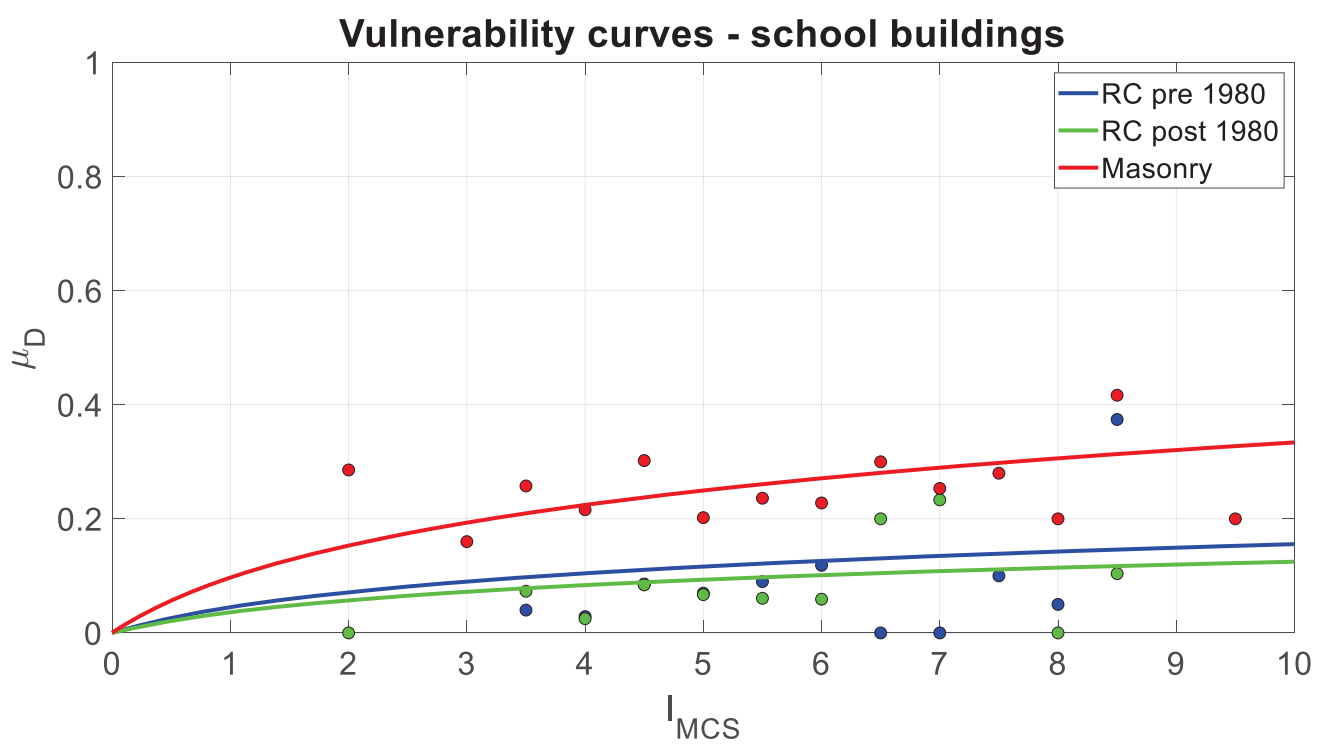

Figure 9: Vulnerability curves of RC and masonry school buildings damaged by Italian earthquakes.

Three points have been obtained for each value of $\mathrm{I}_{\mathrm{MCS}}$ and all points have been fitted by lognormal cumulative functions and by optimizing the problem, assuming the minimum of the sum of squared errors between the set of points and the proposed curve. The result shows that RC buildings designed after 1980 present lower damages also for the highest values of the IM assumed, while the trend increases for RC buildings designed before 1980. Masonry buildings present substantial damages for high values of $\mathrm{I}_{\mathrm{MCS}}$, also arriving at values of $\mu_{\mathrm{D}}$ equal to 0.4 . Overall, the obtained vulnerability curves present a safer scenario for RC buildings than masonry ones. The observed low values of $\mu_{\mathrm{D}}$, also for higher values of IM, requires to better investigate the vulnerability of this typology of buildings, also considering other damage sources. As a matter of fact, it seems that the RC school buildings did not suffer damages.

\section{CONCLUSIONS AND FUTURE DEVELOPMENTS}

This study has analyzed the effects of earthquakes occurred over the last 50 years on the Italian school building portfolio. The data collected in the DA.D.O. platform have been used to perform this investigation. A database including information about masonry and RC school buildings surveyed after Italian earthquakes has been created. A critical discussion of the key features of Italian school buildings, accounting for construction typology, year of construction, number of storeys, area and structural regularity is provided. In addition, a post-processing of the damages suffered after the selected seismic events has been carried out, by providing damage probability matrices for damages on horizontal structures, stairs, roofs and nonstructural elements and vulnerability curves accounting for damages on vertical structural elements.

The results of the statistical investigations have provided a basic idea about the seismic performance of Italian school buildings. The database will be used for future investigations aimed at defining a taxonomy of Italian school building and identifying the main vulnerability sources, basing on the damages suffered during past seismic events. The elaboration of the information collected in the database can assume a key role for future empirical procedures, aimed at investigating the seismic risk at regional scale for school buildings and at providing strategies of seismic risk mapping and reduction. 


\section{REFERENCES}

[1] G. Nicodemo, M. Pittore, A. Masi, V. Manfredi, Modelling exposure and vulnerability from post-earthquake survey data with risk-oriented taxonomies: AeDES form, GEM taxonomy and EMS-98 typologies. International Journal of Disaster Risk Reduction, 50, 101894, 2020.

[2] V. Silva, D. Amo-Oduro, A. Calderon, J. Dabbeek, V. Despotaki, L. Martins, A. Rao, M. Simionato, D. Viganò, C. Yepes, A. Acevedo, N. Horspool, H. Crowley, K. Jaiswal, M. Journeay, M. Pittore, Global earthquake model (GEM) seismic risk map (version 2018.1), 2018. https ://doi.org/10.13117 /gem-global-seism ic-risk-map-2018.1

[3] T. Rossetto, I. Ioannou, D. Grant, Existing empirical fragility and vulnerability functions: compendium and guide for selection, GEM Technical Report 2013-X, GEM Foundation, Pavia, 2013.

[4] V. Silva, S. Akkar, J.W. Baker, P. Bazzurro, J.M. Castro, H. Crowley, M. Dolsek, C. Galasso, S. Lagomarsino, R. Monteiro, D. Perrone, K. Pitilakis, D. Vamvatsikos, Current challenges and future trends in analytical fragility and vulnerability modelling. Earthquake Spectra, 35(4), 1927-1952, 2019.

[5] V. Cerchiello, P. Ceresa, R. Monteiro, N. Komendantova, Assessment of social vulnerability to seismic hazard in Nablus, Palestina. International Journal of Disaster Risk Reduction, 28, 491-506, 2018.

[6] G.J. O’Reilly, R. Monteiro, A.M.B. Nafeh, T.J. Sullivan, G.M. Calvi, Displacementbased framework for simplified seismic loss assessment. Journal of Earthquake Engineering, 2020, doi.org/10.1080/13632469.2020.1730272.

[7] A. Masi, L. Chiauzzi, G. Santarsiero, V. Mafredi, S. Biondi, E. Spacone, C. Del Gaudio, P. Ricci, G. Manfredi, G.M. Verderame, Seismic response of RC buildings during the Mw 6.0 August 24, 2016 Central Italy earthquake: the Amatrice case study. Bulletin of Earthquake Engineering, 17, 5631-5654, 2017. https ://doi.org/10.1007/s1051 8-0170277-5

[8] C. Del Gaudio, P. Ricci, G.M. Verderame, G. Manfredi, Observed and predicted earthquake damage scenarios: the case study of Pettino (L'Aquila) after the 6th April 2009 event. Bulletin of Earthquake Engineering, 14(10), 2643-2678, 2016.

[9] C. Del Gaudio, M. Di Ludovico, M. Polese, G. Manfredi, A. Prota, P. Ricci, G.M. Verderame, Seismic fragility for Italian RC buildings based on damage data of the last 50 years. Bulletin of Earthquake Engineering, 18(5), 2023-2059, 2020.

[10] M. Rota, A. Penna, C.L. Strobbia, Processing Italian damage data to derive typological fragility curves. Soil Dynamics and Earthquake Engineering, 28(10-11),933-947, 2008.

[11] A. Rosti, C. Del Gaudio, M. Rota, P. Ricci, M. Di Ludovico, A. Penna, G.M. Verderame, Empirical fragility curves for Italian residential RC buildings. Bulletin of Earthquake Engineering, 2020, https://doi.org/10.1007/s10518-020-00971-4

[12] G. Zuccaro, F.L. Perelli, D. De Gregorio, F. Cacace, Empirical vulnerability curves for Italian masonry buildings: evolution of vulnerability model from the DPM to curves as a function of acceleration. Bulletin of Earthquake Engineering, 2020, https://doi.org/10.1007/s10518-020-00954-5. 
[13] A. Rosti, M. Rota, A. Penna, Empirical fragility curves for Italian URM buildings. Bulletin of Earthquake Engineering, 2020. https://doi.org/10.1007/s10518-020-00845-9

[14] M. Savoia, N. Buratti, L. Vincenzi, Damage and collapses in industrial precast buildings after the 2012 Emilia earthquake. Engineering Structures, 137,162-180, 2017.

[15] M. Di Ludovico, A. Digrisolo, C. Moroni, F. Graziotti, V. Manfredi, A. Prota, M. Dolce, G. Manfredi, Remarks on damage and response of school buildings after the Central Italy earthquake sequence. Bulletin of Earthquake Engineering, 17, 5679-5700, 2019, https ://doi.org/10.1007/s10518-018-0332-x

[16] B. Borzi, P. Ceresa, M. Favarelli, E. Fiorini, M. Onida, Definition of a prioritization procedure for structural retrofitting of Italian school buildings. COMPDYN 2011 III ECCOMAS Thematic Conference on Computational Methods in Structural Dynamics and Earthquake Engineering: An IACM Special Interest Conference, Programme. Papadrakakis M., Fragiadakis, M., Plevris, V. Corfù, Greece.

[17] D.H. Lang, M.I. Verbicaro, Y. Singh, Seismic vulnerability assessment of hospitals and schools based on questionnaire survey. Kjeller, Norway, 2009.

[18] D. Perrone, G.J. O'Reilly, R. Monteiro, A. Filiatrault, Assessing seismic risk in typical Italian school buildings: From in-situ survey to loss estimation. International journal of disaster risk reduction, 44, 101448, 2020.

[19] M. Morici, C. Canuti, A. Dall'Asta, G. Leoni, Empirical predictive model for seismic damage of historical churches. Bulletin of Earthquake Engineering, 18(13), 6015-6037, 2020 .

[20] G. De Matteis, G. Brando, V. Corlito, Predictive model for seismic vulnerability assessment of churches based on the 2009 L'Aquila earthquake. Bulletin of Earthquake Engineering, 17,4909-36, 2019, doi:10.1007/s10518-019-00656-7.

[21] S. Lagomarsino, Damage assessment of churches after L'Aquila earthquake. Bulletin of Earthquake Engineering, 10 (1), 73-92, 2021, doi:10.1007/ s10518-011-9307-x.

[22] S. Ruggieri, C. Tosto, G. Rosati, G. Uva, G.A. Ferro, Seismic Vulnerability Analysis of Masonry Churches in Piemonte after 2003 Valle Scrivia Earthquake: Post-event Screening and Situation 17 Years Later. International Journal of Architectural Heritage, 1-29, 2020, doi:10.1080/15583058.2020.1841366.

[23] B. Borzi, R. Pinho, H. Crowley, Simplified pushover-based vulnerability analysis for large scale assessment of RC buildings. Engineering Structures, 30(3), 804-820, 2008.

[24] M.A. Aiello, P.L. Ciampoli, A. Fiore, D. Perrone, G. Uva, Influence of infilled frames on seismic vulnerability assessment of recurrent building typologies. Ingegneria Sismica, 34(4), 58-80, 2017.

[25] S. Ruggieri, F. Porco, G. Uva, D. Vamvatsikos, Two frugal options to assess class fragility and seismic safety for low-rise reinforced concrete school buildings in Southern Italy. Bulletin of Earthquake Engineering, 2010, DOI: 10.1007/s10518-020-01033-5.

[26] D. Perrone, M.A. Aiello, M. Pecce, F. Rossi F, Rapid visual screening for seismic evaluation of RC hospital buildings, Structures, 3, 57-70, 2015.

[27] S. Ruggieri, D. Perrone, M. Leone, G. Uva, M.A. Aiello, A prioritization RVS methodology for the seismic risk assessment of RC school buildings. International Journal of Disaster Risk Reduction, 51, 101807, 2020, doi.org/10.1016/j.ijdrr.2020.101807 
[28] Italian National Institute of geophysics and volcanology (INGV), Website, http://www.ingv.it/it/.

[29] L. Faenza, A. Michelini, Regression analysis of MCS intensity and ground motion parameters in Italy and its application in ShakeMap. Geophysical Journal International, 180(3), 1138-1152, 2010, doi:10.1111/j.1365- 246X.2009.04467.x.

[30] F. Braga, M. Dolce, D. Liberatore, A statistical study on damaged buildings and an ensuing review of the MSK-76 scale. In: Proceedings of the 7th European conference on earthquake engineering, Athens, Greece, 431-450, 1982.

[31] G. Di Pasquale, G. Orsini, R.W. Romero, New developments in seismic risk assessment in Italy. Bulletin of Earthquake Engineering, 3(1), 101-128, 2005.

[32] T. Rossetto, A. Elnashai, Derivation of Vulnerability Functions for European-Type RC Structures Based on Observational Data. Journal of Engineering Structures, 25, 12411263, 2003.

[33] S. Lagomarsino, S. Giovinazzi, Macroseismic and mechanical models for the vulnerability and damage assessment of current buildings. Bulletin of Earthquake Engineering, 4(4), 415-443, 2006.

[34] M. Dolce, A. Goretti, Building damage assessment after the 2009 Abruzzi earthquake. Bulletin of Earthquake Engineering, 13, 2241-2264, 2015.

[35] M. Dolce, E. Speranza, F. Giordano, B. Borzi, F. Bocchi, C. Conte, A. Di Meo, M. Faravelli, V. Pascale, Observed damage database of past Italian earthquakes: the Da. DO WebGIS. Bollettino di Geofisica Teorica ed Applicata, 60(2), 141-164, 2019.

[36] C. Baggio, A. Bernardini, R. Colozza, S. Coppari, L. Corazza, M. Della Bella, G. Di Pasquale, M. Dolce, A. Goretti, A. Martinelli, G. Orsini, F. Papa, G. Zuccaro, Field manual for post-earthquake damage and safety assessment and short term countermeasures. In: Pinto A, Taucer F (eds) Translation from Italian: Goretti A, Rota M, JRC Scientific and Technical Reports, EUR 22868 EN-2007, 2007.

[37] http://shake map.rm.ingv.it/shake /archive/

[38] A. Sieberg, Scale MCS (Mercalli-Cancani-Sieberg). Geologie der Erdbeben, Handbuch der Geophysik, 2, 552-55, 1930.

[39] Italian Ministry of University and Research (MIUR), Portale unico della scuola (2019) Website: https://dati.istruzione.it/ (In Italian).

[40] https://github.com/anhelus/reverse-geocoding 